\title{
Amyloid Imaging in Dementia: Contribution or Confusion?
}

$\mathbf{T}$

here is mounting evidence and enthusiasm for molecular imaging contribution to the diagnosis of neurodegenerative dementia. A key advance in the imaging field has been the development of selective ligands that can reveal the presence of pathologic deposition of $\mathrm{A} \beta$ amyloid in the cerebral cortex, consistent with dementia due to Alzheimer disease (AD) or a related neurodegeneration (1). Recently, 3 amyloid-avid radiotracers with potential for clinical use have been developed (2) and are approved for use by the U.S. Food and Drug Administration and by European regulators. The Society of Nuclear Medicine and Molecular Imaging, together with the Alzheimer Association, convened a panel of content experts to recommend the appropriate use of these new tools (3). Conservatively, the panel recommended as the first indication the use of amyloid imaging probes to distinguish patients with frontotemporal dementias (FTDs) from patients with amyloid-dependent neurodegenerations, such as typical AD, and a significant proportion also of patients with dementia with Lewy bodies. The clinical rationale for this application follows from the recognition that the diagnosis of FTD can be difficult (4-6) and may be missed in as many as $70 \%$ of patients (7). This circumstance

\section{See page 386}

can lead to inappropriate use of symptomatic medications and incorrect prognostication and, even more importantly, may limit the accuracy and power of future therapeutic trials focused on FTD versus AD pathologic pathways. The recommended use of amyloid imaging in dementia includes focus on patients with features atypical of $\mathrm{AD}$, including prominent aphasia or prominent frontal lobe dysfunction, or with relatively early age of dementia onset; each of these features increases the likelihood of an FTD variant over AD.

In this issue of The Journal of Nuclear Medicine, Kobylecki et al. (8) report their experience with ${ }^{18} \mathrm{~F}$-florbetapir in the distinction of FTD versus $A D$ in demented patients recruited from a universityaffiliated cognitive disorders clinic. The intent of the research was to assess the ability of the radiofluorinated tracer to reproduce the previously published results of amyloid imaging with ${ }^{11} \mathrm{C}$-Pittsburgh compound B from several laboratories (9-11). In essence, patients with clinical presentations favoring FTD over AD should have negative amyloid scan results, and patients with $\mathrm{AD}$ should have positive scan results. However, as often encountered in biomedical research, the study results may raise as many questions as they

Received Jan. 14, 2015; revision accepted Jan. 19, 2015.

For correspondence or reprints contact: Kirk A. Frey, University of Michigan, University of Michigan Hospitals, Rm. B1 G5-5 UH, 1500 East Medical Center Dr., Ann Arbor, MI 48109-0028.

E-mail: kfrey@umich.edu

Published online Feb. 5, 2015.

COPYRIGHT (C 2015 by the Society of Nuclear Medicine and Molecular Imaging, Inc.

DOI: $10.2967 /$ jnumed.114.151571 answer. Kobylecki et al. report that the recommended clinical interpretation approach to ${ }^{18} \mathrm{~F}$-florbetapir scans resulted in identification of positive patterns in $25 \%$ of FTD and in $10 \%$ of normal comparison subjects. They identified positive scans in $80 \%$ of AD subjects. These findings raise critically important issues: are the rating recommendations and rules for clinical amyloid reporting suboptimal? Do the clinical diagnostic amyloid tracers perform differently from predictions based on the research amyloid tracer ${ }^{11} \mathrm{C}$-Pittsburgh compound B?

There are several considerations that may account for apparent discord between clinical diagnoses and ${ }^{18} \mathrm{~F}$-florbetapir interpretations. First, the clinical diagnoses may be inaccurate. It is well established that clinical classification differs from autopsy diagnosis in a significant proportion of dementia cases (12). In the present study, the investigators used also ${ }^{18}$ F-FDG PET brain imaging, confirming that FTD patients had prominent frontal lobe hypometabolism. This feature, however, is also fallible in the diagnosis of FTD when compared with autopsy confirmation $(13,14)$. Thus, the discrepant amyloid versus clinical classification results of the Kobylecki study add to reports suggesting potential diagnostic gain from the imaging (15-18), even beyond the contribution of ${ }^{18} \mathrm{~F}-$ FDG PET characterizations. The authors offer the possibility of multiple pathologies in some of their subjects as another explanation, noting particularly the potential impact of apolipoprotein E $\varepsilon 4$ genotype on promotion of amyloid deposition. Although the effect of apolipoprotein E cannot be not excluded, the cooccurrence of FTD and fibrillary amyloid deposition is only rarely reported and is notably absent from most series of autopsy dementia evaluation (15). Only autopsy confirmation of dementia pathology in the currently reported cases will reveal the truth underlying the apparent disparities in the Kobylecki report.

Of much greater concern, however, is the performance of visual image interpretations by observers, who had undergone the recommended training experience before the study. Of 28 subject scans analyzed, there was a lack of concordance among the 4 independent raters in 11 cases and only a modest statistical assessment of interrater agreement. This suggests the need for additional analytic approaches to clinical reading and reporting of amyloid images. To be sure, the studies interpreted by Kobylecki et al. are challenging. Most FTD patients have significant neocortical atrophy in frontal or temporal lobes, and this may cause interpretative difficulty with tracers in subcortical white matter appearing potentially of cerebrocortical origin. Another potential source of imaging error in cognitively impaired patients is subject motion during scanning that can worsen the influence of adjacent subcortical white matter on assessment of the gray matter tracer uptake. In the present study, the potential effect of subject motion was reduced by means of a dynamic series of images over 50-60 min after injection with motion-correction image realignment. Automated MR imaging-based cerebrocortical tracer uptake values were obtained from PET voxels classified as gray matter on T1-weighted MR imaging in parallel with the visual analyses, and these quantitative data suggested better overall agreement with clinical diagnostic classifications than the visual reads. Missing from the report 
are open reconciliations of interpreters' visual interpretations with the combined PET/MR image displays that could inform as to the nature of inconsistent and potentially misleading qualitative analyses.

In conclusion, the report of Kobylecki et al. provides additional evidence that clinical use of amyloid imaging has the potential to contribute to dementia diagnosis, beyond specialist clinical characterizations and ${ }^{18} \mathrm{~F}$-FDG PET imaging. However, more sophisticated training of image interpreters and consideration of multimodality image display and review approaches may be needed to realize accurate diagnostic amyloid scanning performance in patients with suspected FTD.

\section{DISCLOSURE}

Kirk A. Frey is a consultant to AVID Radiopharmaceuticals, MIM Software, and Siemens. He has grant support from General Electric and owns common stock in Bristol Myers Squibb, General Electric, Johnson \& Johnson, Medtronic, Merck, and Novo Nordisk. No other potential conflict of interest relevant to this article was reported.

Kirk A. Frey University of Michigan Ann Arbor, Michigan

\section{REFERENCES}

1. Klunk WE, Engler H, Nordberg A, et al. Imaging brain amyloid in Alzheimer's disease with Pittsburgh compound-B. Ann Neurol. 2004;55:306-319.

2. Rowe CC, Villemagne VL. Brain amyloid Imaging. J Nucl Med. 2011;52:1733-1740.

3. Johnson KA, Minoshima S, Bohnen NI, et al. Appropriate use criteria for amyloid PET: a report of the Amyloid Imaging Task Force, the Society of Nuclear Medicine and Molecular Imaging, and the Alzheimer's Association. $J$ Nucl Med. 2013;54:476-490.
4. Varma AR, Snowden JS, Lloyd JJ, Talbot PR, Mann DM, Neary D. Evaluation of the NINCDS-ADRDA criteria in the differentiation of Alzheimer's disease and frontotemporal dementia. J Neurol Neurosurg Psychiatry. 1999;66:184188.

5. McKhann GM, Albert MS, Grossman M, Miller B, Dickson D, Trojanowski JQ. Clinical and pathological diagnosis of frontotemporal dementia. Arch Neurol. 2001;58:1803-1809.

6. Mendez MF, Shapira JS, McMurtray A, Licht E, Miller BL. Accuracy of the clinical evaluation for frontotemporal dementia. Arch Neurol. 2007;64:830-835.

7. Piguet O, Hornberger M, Shelley BP, Kipps CM, Hodges JR. Sensitivity of current criteria for the diagnosis of behavioral variant frontotemporal dementia. Neurology. 2009;72:732-737.

8. Kobylecki C, Langheinrich T, Hinz R, et al. ${ }^{18} \mathrm{~F}$-florbetapir positron emission tomography in patients with frontotemporal dementia and Alzheimer's disease. $J$ Nucl Med. 2015;56:386-391.

9. Rowe CC, Ng S, Ackermann U, et al. Imaging beta-amyloid burden in aging and dementia. Neurology. 2007;68:1718-1725.

10. Rabinovici GD, Furst AJ, O'Neil JP, et al. ${ }^{11} \mathrm{C}$-PIB PET imaging in Alzheimer disease and frontotemporal lobar degeneration. Neurology. 2007;68:1205-1212.

11. Engler H, Santillo AF, Wang SX, et al. In vivo amyloid imaging with PET in frontotemporal dementia. Eur J Nucl Med Mol Imaging. 2008;35:100-106.

12. Knopman DS, DeKosky ST, Cummings JL, et al. Practice parameter: diagnosis of dementia (an evidence-based review) - report of the Quality Standards Subcommittee of the American Academy of Neurology. Neurology. 2001;56:1143-1153.

13. Foster NL, Heidebrink JL, Clark CM, et al. FDG-PET improves accuracy in distinguishing frontotemporal dementia and Alzheimer's disease. Brain. 2007;130: 2616-2635.

14. Womack KB, Diaz-Arrastia R, Aizenstein HJ, et al. Temporoparietal hypometabolism in frontotemporal lobar degeneration and associated imaging diagnostic errors. Arch Neurol. 2011;68:329-337.

15. Burke JF, Albin RL, Koeppe RA, et al. Assessment of mild dementia with amyloid and dopamine terminal positron emission tomography. Brain. 2011;134: 1647-1657.

16. Ossenkoppele R, Prins ND, Pijnenburg YA, et al. Impact of molecular imaging on the diagnostic process in a memory clinic. Alzheimers Dement. 2013;9:414-421.

17. Sánchez-Juan P, Ghosh PM, Hagen J, et al. Practical utility of amyloid and FDGPET in an academic dementia center. Neurology. 2014;82:230-238.

18. Banzo I, Jiménez-Bonilla J, Ortega-Nava F, et al. Amyloid imaging with ${ }^{11} \mathrm{C}-\mathrm{PIB}$ $\mathrm{PET} / \mathrm{CT}$ and glucose metabolism with ${ }^{18} \mathrm{~F}$-FDG PET/CT in a study on cognitive impairment in the clinical setting. Nucl Med Commun. 2014;35:238-244. 